\title{
What are the "Doses," Timing, and Treatment of Childhood Depression That Impact Adulthood?
}

Leslie A. Hulvershorn MD, MSc

Adolescent Behavioral Health Research Program, Indiana University School of Medicine, Indianapolis

Depression creates more burden globally than nearly any other physical or mental disorder, yet surprisingly, little is known about what can be done to prevent its onset and, as Copeland et al., ${ }^{1}$ in this issue of $J A A C A P$, address, what the long-term outcomes of youth depression are. The existing medical literature on outcomes of child and adolescent depression is large enough for 2 recent reviews, ${ }^{2,3}$ which point out the key gaps in our understanding. Does childhood depression actually worsen adult outcomes, or is the driver really all the associated childhood adversity and comorbidity? Although we know women suffer disproportionately from depression, are childhood predictors specific to girls or boys? Is it worse to have many episodes of depression in one's youth than a few? Do subthreshold depressive symptoms impact adulthood too? Finally, is it important, in adulthood, whether depression began in childhood or adolescence?

To shed light on these understudied issues, Copeland et al. ${ }^{1}$ examined data from the over 2 decades-long study, longitudinal Great Smoky Mountains Study (GSMS), consisting of children

This is the author's manuscript of the work published in final edited form as:

Hulvershorn, L. A. (2021). Editorial: What are the "Doses," Timing, and Treatment of Childhood Depression That Impact Adulthood? Journal of the American Academy of Child \& Adolescent Psychiatry, 60(5), 570-572. https://doi.org/10.1016/j.jaac.2020.12.015 
from 11 predominantly rural counties in North Carolina. ${ }^{4}$ Data from 3 cohorts of children, ages 9, 11 , and 13 years old, were extracted from a dataset of 12,000 children, resulting in 1,420 participants (49\% female participants) oversampled for youth depression. Annual assessments were completed with youth and parents until age 16 and then again without parents at ages 19, 21, 25, and 30. Depression was defined as DSM-IV major depression, dysthymia, and depression not otherwise specified, where a present episode was any endorsement of sufficient symptoms over the past 3 months. Socioeconomic status, unstable family structure and dysfunction, maltreatment, and peer victimization were also assessed. In addition, use of youth mental health services was identified. ${ }^{5}$ Adult functioning was assessed across 4 domains: health, risky or illegal behaviors, wealth (financial and educational), and social function. Regression models were used to determine differences in adult outcomes by childhood and adolescent depression status.

Regarding the findings of the study, somewhat unsurprisingly, childhood and adolescent depression was associated with elevated rates of adult anxiety, depression, and substance use disorders. Childhood and adolescent depression was also associated with worse adult functional outcomes: physical health, risky or criminal behavior, financial and educational, and social functions. Importantly, these effects of early depression appear to be independent of other childhood psychiatric comorbidities and adversities. Of note, when depressive behaviors were considered only at ages 25 and 30, childhood depression continued to be associated with diagnostic, substance, health, and social outcomes, but not with risky or criminal behavior or financial and educational outcomes, as was seen at ages 19 and 21 . Readers may be surprised to learn that a child's biological sex was not associated with adult outcomes. The authors helpfully note that "although the mechanisms by which depression emerges differ by sex, the mechanisms 
by which depression affects later outcomes appears to be shared." Given that this finding is somewhat counterintuitive, it seems to warrant replication in additional samples.

Perhaps the study's most interesting findings pertain to the influence of the amount, timing and treatment of depression during childhood and adolescence on adult outcomes. As expected, the risk of poor adult outcomes was elevated for those with higher levels of exposure to cumulative depression. The important nuance here is that subthreshold depressive symptoms also showed associations (albeit weaker) with adult depression and functional outcomes, even if subjects never met full $D S M-I V$ criteria for depression in their youth. The authors summarize that "it is not merely a diagnosis of depression that is associated with long term outcomes, but the persistence of elevated levels of depressive symptoms." For most adult outcomes, there were no differences in risk based on age of onset. Although for anxiety disorders and social problems, adolescent-onset depression was more strongly associated than the childhood-onset form. The authors note that this finding runs counter to previous conceptualizations of child-onset depression as a distinct subtype with the poorest prognosis.6, 7, 8, 9 Finally, the authors identified a positive effect of treatment of childhood depression on adult diagnostic status and found that receipt of specialized mental health services (vs primary care treatment) was associated with lower risk for any adult psychiatric disorder, with the greatest influence on adult anxiety disorders (ie, treated subjects were almost half as likely to have diagnoses in young adulthood with an anxiety disorder). Interestingly, and unfortunately, treatment of youth depression did not influence nonpsychiatric adult functional outcomes.

Although this analysis of the GSMS dataset provides a number of important new findings, it is worth reflecting that it addresses only psychiatric and functional outcomes associated with childhood and adolescent unipolar depression in young adults (up to age 30). Although the 
rationale for excluding mood symptoms associated with bipolar disorder and schizoaffective disorder is sound (ie, low incidence), these disorders, when present in youth, may have adult outcomes distinct from the forms of unipolar depression studied by Copeland et al. ${ }^{1}$ Adulthood, as defined in this study, is still only a very early window into later life, and findings may differ substantially in later decades. Of course, study samples extending from childhood into midadulthood are difficult and costly to maintain, but are necessary to answer such questions, and hopefully future analyses with this and other samples will address this area.

This work validates the enormously important findings of how impactful early depression is.10, 11, 12 Reports of innovative but intuitive findings that subthreshold depression can also influence adult outcomes question prior conceptualizations that child-onset depression is more deleterious than adolescent-onset10,11, 12 and finds that treatment of youth depression yields some benefit on anxiety disorders during young adulthood, an observation which has not been reported previously. ${ }^{13}$ Given the fairly low effect size of treatment of depression in youth, ${ }^{14}$ any long- term benefit is welcome news for the field. Thus, this work frames the need for effective preventive and treatment interventions, given the potentially lifelong impact of youth depression (even subthreshold forms) and provides hope that treatments we have are worth amplifying and spreading.

Unfortunately, despite sound methods and a reasonable sample size, individual child-level characteristics that could generate "high risk" groups (and therefore targets for personalized treatment studies) eluded the researchers. It may be that this sample and these methods are not sufficient to detect true characteristics, but more likely, clinically observable data (eg, symptom counts from parent and child report questionnaires) do not provide the specificity needed for this type of fine-grained classification. Genetic, physiological, and brain-based data collected in 
longitudinally followed samples may provide the framework needed. The authors suggest that efforts to reduce children's exposure to depression through reduction in psychosocial risk factors (eg, caregiver instability and maltreatment) ${ }^{15,16}$ is the public heath "take away" from their work. They hint at the Herculean task that this would be for society. Better stratification to determine which children are most vulnerable to depression would certainly make targeted psychosocial efforts more feasible. Finally, functional outcomes in young adults were not impacted by youth treatment, even when that care came from specialized settings. This finding suggests the need for novel depression treatment efforts that could be expanded from existing treatments to target employment, education, and physical health targets in youth, in the hopes that treatments sustain adult functionality as well. Until those and other innovations are developed, this study highlights the imperative to expand access to quality specialty care for youth with depression. 


\section{References}

1. Copeland WE, Alaie I, Jonsson U, Shanahan L. Associations of childhood and adolescent depression with adult psychiatric and functional outcomes. J Am Acad Child Adolesc Psychiatry. 2021;60:604-611.

2. Johnson D, Dupuis G, Piche J, Clayborne Z, Colman I. Adult mental health out-comes of adolescent depression: a systematic review. Depress Anxiety. 2018;35(8): 700-716.

3. Clayborne ZM, Varin M, Colman I. Systematic review and meta-analysis: adolescent depression and long-term psychosocial outcomes. J Am Acad Child Adolesc Psychiatry. 2019;58(1):72-79.

4. Costello EJ, Angold A, Burns BJ, Erkanli A, StangI DK, Tweed DL. The Great Smoky Mountains Study of Youth. Functional impairment and serious emotional disturbance. Arch Gen Psychiatry. 1996;53(12):1137-1143.

5. Schwartz KTG, Bowling AA, Dickerson JF, et al. The child and adolescent services assessment: interrater reliability and predictors of rater disagreement. Adm Policy Ment Health. 2018;45(6):944-957.

6. Weissman MM, Wolk S, Wickramaratne $\mathrm{P}$, et al. Children with prepubertal-onset major depressive disorder and anxiety grown up. Arch Gen Psychiatry. 1999;56(9):794-801.

7. Kaufman J, Martin A, King RA, Charney D. Are child-, adolescent-, and adult-onset depression one and the same disorder? Biol Psychiatry. 2001;49(12):980-1001.

8. Kovacs M, Devlin B, Pollock M, Richards C, Mukerji P. A controlled family history study of childhood-onset depressive disorder. Arch Gen Psychiatry. 1997;54(7):613-623.

9. Wickramaratne PJ, Greenwald S, Weissman MM. Psychiatric disorders in the relatives of 
probands with prepubertal-onset or adolescent-onset major depression. J Am Acad Child Adolesc Psychiatry. 2000;39(11):1396-1405.

10. Harrington R, Bredenkamp D, Groothues C, Rutter M, Fudge H, Pickles A. Adult outcomes of childhood and adolescent depression. III. Links with suicidal behaviours. J Child Psychol Psychiatry. 1994;35(7):1309-1319.

11. Kovacs M, Goldston D, Gatsonis C. Suicidal behaviors and childhood-onset depressive dis-orders: a longitudinal investigation. J Am Acad Child Adolesc Psychiatry. 1993;32(1):8-20.

12. Weissman MM, Wolk S, Goldstein RB, et al. Depressed adolescents grown up. JAMA. 1999;281(18):1707-1713.

13. Kovacs M, Obrosky S, George C. The course of major depressive disorder from childhood to young adulthood: recovery and recurrence in a longitudinal observational study. J Affect Disord. 2016;203:374-381.

14. Eckshtain D, Kuppens S, Ugueto A, et al. Meta-analysis: 13-year follow-up of psychotherapy effects on youth depression. J Am Acad Child Adolesc Psychiatry. 2020; 59(1):45-63. 15. Shanahan L, Copeland WE, Costello EJ, Angold A. Child-, adolescent- and young adultonset depressions: differential risk factors in development? Psychol Med. 2011;41(11):22652274.

16. Jaffee SR, Moffitt TE, Caspi A, Fombonne E, Poulton R, Martin J. Differences in early childhood risk factors for juvenile-onset and adult-onset depression. Arch Gen Psychiatry. 2002;59(3):215-222. 